\title{
APROBACIÓN PRESIDENCIAL Y CLARIDAD DE LA RESPONSABILIDAD EN UN CONTEXTO DE CAMBIO POLÍTICO E INSTITUCIONAL: EL CASO URUGUAYO'
}

\author{
Lucía Selios ${ }^{2}$
}

\section{Resumen}

¿Cómo evalúan los uruguayos a sus presidentes? ¿Lo hacen según el modelo cíclico de aprobación característico de los sistemas presidencialistas con mandatos fijos? El modelo cíclico de aprobación implica que los mandatos comienzan con una "luna de miel" marcando altos niveles de aprobación, luego decrece y nuevamente se recupera al final del período. En Uruguay los datos muestran que este patrón se presenta en las cuatro últimas administraciones, pero no para las primeras tres de la serie (desde 1985 al 1999). De hecho, en ellas no se registran lunas de miel y los niveles de aprobación son bajos e impredecibles. ¿Cómo se explican los cambios en la dinámica de la aprobación presidencial? El artículo argumenta que se debe a los cambios introducidos en la reforma constitucional de 1997 y en el reequilibrio del sistema de partidos. Usando datos del Executive Approval Project analiza algunas implicaciones observables de este argumento. El análisis temporal muestra que, bajo los nuevos contextos institucionales, el apoyo popular al presidente crece, aumentando la "claridad de la respon-

\footnotetext{
${ }^{1}$ Agradezco especialmente a Ryan Carlin por animarme a escribir este artículo. A Cecilia Martínez-Gallardo por su paciente acompañamiento, a Fabricio Carneiro, Germán Bidegain y Daniela Vairo y a los revisores por sus útiles comentarios y consejos. A ellos mis agradecimientos y los errores todos míos. Este trabajo fue presentado, gracias a la ayuda económica de CSIC - UdelaR en APSA Annual Meeting 2018. En el panel: "Understanding Public Support for Executives in Different Democratic Systems". Los comentarios de todos los asistentes, en especial los del comentarista Aníbal Pérez Liñán y Jonathan Hartlyn fueron de gran ayuda. Algunos se reflejan aquí y otros servirán para profundizar en próximos trabajos.

${ }^{2}$ Profesora adjunta del Departamento de Ciencia Política de la Facultad de Ciencias Sociales, Universidad de la Republica. E-mail: lucia.selios@cienciassociales.edu.uy.
} 
sabilidad" que permite a los ciudadanos evaluar a sus presidentes según el resultado de las políticas económicas y el ciclo electoral. Por esta razón, la dinámica se vuelve cíclica. En definitiva, a través del análisis del caso uruguayo este artículo intenta brindar evidencia sobre la importancia del diseño institucional en la aprobación de la gestión presidencial.

Palabras clave: opinión pública - aprobación presidencial instituciones políticas

\section{Abstract}

How do Uruguayans valuate their presidents? Do they evaluate them according to the cycle model of approval observed in presidential systems with fixed terms? The cyclical model of approval begins with a "honeymoon" of high approval which then decreases only to improve towards the end of the presidential term. In Uruguay, the results show that this pattern indeed holds for the last four presidential terms, but not for the previous three (from 1985 to 1999). These terms do not indeed register honeymoons and approval is low and unpredictable. What explains these changes in the dynamics of presidential approval? This paper argues that it is due to institutional changes introduced in the 1997's Constitution and new party system equilibrium. Using measures derived from the Executive Approval Project, it tests some of the empirical implications of this argument. This cross-temporal analysis suggests that, under the new institutional contexts, support for the president increases, bolstering "clarity of responsibility" and allowing citizens to evaluate their presidents based on results of political performance and electoral cycle. For this reason, the pattern of approval turns cyclical. In sum, by analyzing the Uruguayan case, this paper tries to provide evidence as to the importance of institutional design in citizens' approval of the president's performance.

Keywords: public opinion - presidential approval - political institutions 


\section{Introducción}

El estudio de la evaluación presidencial es importante para entender el funcionamiento de las democracias. En los sistemas presidencialistas, si existe adecuada claridad de responsabilidad, el jefe del ejecutivo es visto como principal responsable de los éxitos y fracasos de una gestión de gobierno, por lo que la variación en las opiniones ciudadanas opera como un mecanismo de accountability vertical interelectoral (O'Donnell, 2007). Las fuertes bajas en los niveles de aprobación, por ejemplo, tienen un impacto directo en los cambios de preferencias electorales, así como en los rumbos de las agendas de gobierno (Carlin, Love \& Martínez-Gallardo, 2015a) y son predictores bastante fiables de interrupciones de los mandatos presidenciales (Pérez-Liñán, 2007).

En Uruguay, son escasos los artículos que indagan en las causas de la aprobación presidencial. Los pocos trabajos disponibles muestran que allí, tal como se espera teóricamente, los niveles de aprobación dependen de la situación económica por la que atraviesa al país (Rius, 1992; Luna, 2002; Carlin \& Hunt, 2015). Sin embargo, aún no se ha estudiado cómo ha sido la dinámica de aprobación durante las administraciones de gobierno, por lo que las primeras preguntas que guian este trabajo son, ¿cómo se evalúa a los presidentes durante los períodos de gobierno en Uruguay? ¿Han mantenido en el tiempo similares niveles de aprobación? ¿Siguen el modelo cíclico de aprobación característico de los sistemas presidencialistas con mandatos fijos?

En un reciente trabajo sobre aprobación en América Latina, Carlin, Hartlyn, Hellwig, Love, Martínez-Gallardo \& Singer (2018) señalan que en sistemas presidenciales con mandatos fijos lo habitual es encontrar que la aprobación sigue un modelo cíclico, con altos niveles de apoyo inicial, asociados al fenómeno de "luna de miel", disminución gradual y posterior recuperación de los niveles de aprobación hacia el final del mandato. Pero encuentran que esto no siempre ha sido así y evidencian varios casos atípicos o out- 
liers entre los que se encuentran los primeros tres periodos presidenciales posteriores a 1985 en Uruguay.

Cuando se analizan las series de aprobación en dicho país, el diagnóstico es correcto, el patrón cíclico no aparece sino hasta la administración que comienza en el año 2000 y los promedios de aprobación son muy bajos. Por lo que rápidamente se puede responder que en Uruguay no siempre se ha evaluado la gestión de los gobiernos según el modelo cíclico de aprobación. Pero entonces, ¿cómo se explican los cambios en los niveles y en la dinámica de la aprobación presidencial durante los períodos de gobierno?

Vasta literatura argumenta que las instituciones, tanto sean reglas electorales como características de un sistema político, impactan en la forma en la que los ciudadanos evalúan a los presidentes, porque pueden otorgarles mayor respaldo popular y de esta manera favorecen u obstaculizan la claridad de responsabilizar ${ }^{3}$ (clarity of responsibility), o sea, la capacidad ciudadana para clarificar la responsabilidad política de sus representantes, en particular del presidente (Powell y Whitten, 1992).

La literatura también señala que las instituciones modifican la claridad de la responsabilidad, ya que alteran la forma en que se divide el poder, en particular del peso que tienen los veto players en el sistema político (Carlin et al., 2015a). Asi, por ejemplo, si el gobierno controla la bancada mayoritaria en el legislativo tenderá a ser responsabilizado por el bienestar de la población, mientras que esta responsabilidad se puede diluir si la mayoría del parlamento es controlado por la oposición. Lo mismo sucede con los poderes del presidente o la cantidad de partidos que forman la coalición de gobierno e incluso el porcentaje de votos con el que el presidente es electo. De esta manera, la existencia de parlamentos bicamerales, gobiernos de coalición, gobiernos

\footnotetext{
${ }^{3}$ La traducción más apropiada sería "claridad para responsabilizar"; sin embargo, en la literatura en castellano el concepto se denomina "claridad de responsabilidad" o "claridad de la responsabilidad".
} 
en minoría e incluso diferentes niveles de descentralización política y económica (León, 2010) pueden diluir la capacidad ciudadana para responsabilizar a sus gobernantes.

Este trabajo de tipo observacional se limita a describir y argumentar ${ }^{4}$ que los cambios registrados en las series de evaluación presidencial en Uruguay, tanto en el nivel de apoyo como en la dinámica temporal, se deben a modificaciones del contexto institucional que se produjeron a inicios del siglo XXI en el pais, particularmente en el sistema electoral y de partidos. Se entiende que los cambios institucionales afectaron los niveles de aprobación al modificar la forma en la que los ciudadanos apoyan y son capaces de asignar al presidente la responsabilidad por los resultados de las políticas, generando cambios en los predictores de los niveles de aprobación presidencial.

A través del caso uruguayo, el artículo aporta una primera aproximación a la relación entre dinámica de aprobación e instituciones políticas en el país. Para ello, comienza con una descripción de los cambios institucionales y políticos en Uruguay e indaga de qué manera impactaron en los niveles de aprobación presidencial. El artículo propone un marco interpretativo sobre cómo las instituciones inciden en la dinámica de aprobación, utilizando los conceptos de claridad de responsabilidad y voto económico. Posteriormente, se presentan las especificaciones metodológicas y a continuación se explican los cambios en la dinámica de la aprobación presidencial, según la incidencia de la economía, el ciclo de gobierno y el respaldo electoral del presidente antes y después del cambio institucional. El trabajo finaliza con algunas reflexiones sobre diseño institucional y aprobación presidencial, planteando algunas alternativas y pensando en la dinámica de aprobación para futuras administraciones de gobierno.

\footnotetext{
${ }^{4}$ Se comparte la opinión de que un posterior análisis experimental puede poner a prueba de manera más concluyente la densa descripción y supuestos que este trabajo defiende.
} 


\section{Diseño institucional, aprobación y después...}

La democracia uruguaya es una de las más antiguas y mejor ranqueadas del continente (The Polity IV, Freedom House). Se trata de un sistema presidencialista, con mandatos fijos de 5 años sin reelección inmediata. A diferencia de otras democracias de la "tercera ola", cuenta con partidos longevos, un sistema de partidos institucionalizado e internamente fragmentado, fuerte disciplina partidaria y bajos niveles de corrupción. La competencia política se ordena por la distinción ideológica del eje izquierda-derecha y la opinión pública presenta altos niveles de apoyo y evaluación de la democracia, y cuenta con una matriz estado-céntrica nacida a comienzos del siglo XX. Pero no le son ajenos los problemas estructurales de las democracias incipientes, como desigualdad económica y social, lenta inclusión de mujeres en la política, históricas prácticas de clientelismo y patronazgo, entre otras. Esta combinación de características hace del país un caso atractivo para analizar el peso de las instituciones y contextos en la opinión pública, en particular en las formas en las que los ciudadanos evalúan a sus presidentes, vinculado al contexto institucional.

En particular, desde 1985, después de la última dictadura militar, el país pasó por una rápida transición hasta recuperar, muy pronto, su sistema político. Durante los siguientes 30 años se han mantenido los niveles democráticos, moderada polarización ideológica y gradual cambio de preferencias electorales (Luján \& López, 2015). Por su parte, en estos años la opinión pública ha presentado niveles de identificación partidaria altos y estables, confianza institucional y apoyo a la democracia (Vario \& Rodríguez, 2017). Además, los tres principales partidos políticos (Partido Colorado, Partido Nacional y Frente Amplio) se han alternado en el gobierno.

Al analizar las series de aprobación presidencial (Gráfico 1) se aprecia que las primeras administraciones no registraron el fenómeno de "luna de miel" ni siguen un patrón de variación específico. Este periodo incluye los gobiernos del Partido Colorado de posdictadura (Julio María Sanguinetti - 
1985-1990), ${ }^{5}$ del Partido Nacional (Luis Alberto Lacalle 1990-1995) y el segundo de Julio María Sanguinetti (19952000), del Partido Colorado. En cambio, las posteriores administraciones de gobierno si presentan la dinámica cíclica de aprobación, en particular la encabezada por Jorge Batlle (2000-2005) ${ }^{6}$ del Partido Colorado y los siguientes tres períodos del Frente Amplio, Tabaré Vázquez (2005-2010), José Mujica (2010-2015) y nuevamente Tabaré Vázquez (2015 a la fecha). El cambio en el patrón de aprobación se relaciona con los cambios en el contexto político-institucional que se produjeron a inicios del siglo XXI. Especificamente, un cambio en las reglas electorales que rigen a partir de la elección de 1999 y la consolidación de un nuevo equilibrio en el sistema de partidos (Buquet y Piñeiro, 2014).

Los análisis de aprobación presidencial en Uruguay han sido escasos y sus perspectivas analíticas diferentes, pero todos ellos destacan la importancia de la economía como predictor de los niveles de aprobación presidencial. Los dos primeros estudios (Rius, 1992; Luna, 2002) utilizan datos agregados anuales, variables macroeconómicas y también subjetivas para establecer los predictores de los niveles de aprobación. Estudian períodos anteriores al cambio en la dinámica de aprobación presidencial en el país. Ambos encuentran la relevancia que la situación económica tiene sobre la evaluación. Luna señala que "en el nivel agregado, la opinión pública responde ante las condiciones objetivas de la economía y lo hace en forma consistente" (2002:148) en particular, a la inflación y el desempleo. ${ }^{7}$

\footnotetext{
${ }^{5}$ Para este primer mandato no se tiene la información del primer año de gobierno, pero es posible pensar que tampoco tuvo luna de miel, tal como sucedió en las siguientes administraciones.

${ }^{6}$ Durante la administración de Jorge Batlle, el país sufrió una fuerte crisis económica y recesión de pagos, altos niveles de desempleo, inflación y desconfianza en el sistema financiero. Por ello, los magros niveles de aprobación, que comenzaron muy bien, sufrieron una caída importante que afecta el promedio general del periodo. Sin embargo, tal como las demás a partir de esta, al final del mandato subió el nivel de aprobación.

${ }^{7}$ En el análisis de largo plazo de aprobación presidencial, es la inflación mas no el desempleo lo que influye (Luna, 2002:147).
} 
Gráfico 1. Evolución de la aprobación presidencial en Uruguay según períodos de gobierno (1986-2016 por trimestres)

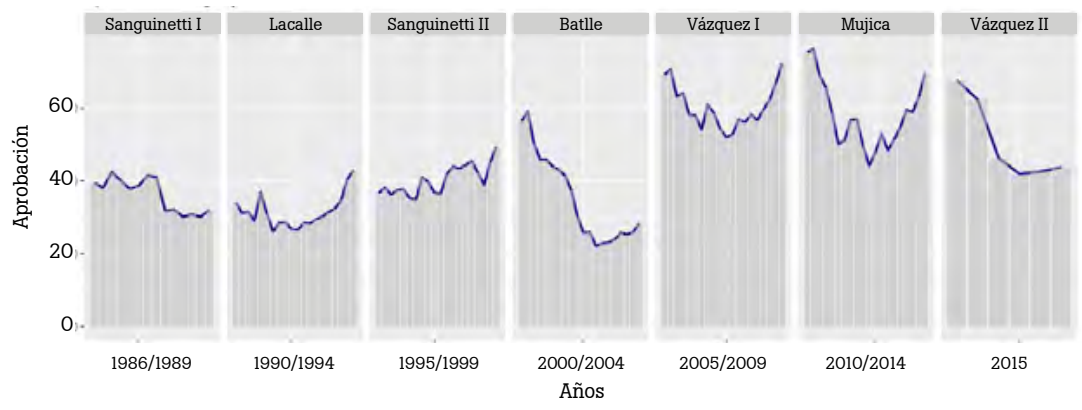

Fuente: Los datos de aprobación trimestral corresponden al Executive Approval Project periodo 1986-2016.

El otro trabajo, Carlin y Hunt (2015) encuentra que los uruguayos se comportan como inversores a la hora de evaluar a su presidente o sea que proyectan sus perspectivas económicas egocéntricas (personales) antes que las retrospectivas a la evaluación presidencial. Estos autores realizan análisis con datos individuales posteriores al año 2000, cuando la evaluación presidencial asume el modelo cíclico de aprobación característico de los regímenes presidenciales, por lo que tal vez su hallazgo esté relacionado al cambio en los predictores económicos sobre la aprobación vinculado al nuevo diseño institucional.

\section{Reforma constitucional y aprobación presidencial}

El Uruguay se caracteriza por ser un presidencialismo con un parlamento bicameral, con elecciones concurrentes cada cinco años donde no se permite la reelección inmediata. El voto es obligatorio y los partidos o "lemas" presentan listas bloqueadas y cerradas a distintos órganos en una única hoja de votación. Además, en materia de democracia directa el Uruguay cuenta con varios mecanismos de referéndums y plebiscitos tanto por iniciativa legislativa como popular. En 1996 se plebiscitó una constitución promulgada en 1997, 
cuyas reglas se aplicaron para la elección de 1999 y la administración electa que asumió en el año 2000.

La nueva normativa introdujo varias modificaciones electorales y de gobierno. En cuanto al gobierno, la reforma concentró el poder en el presidente y le otorgó aún más iniciativa a la hora de incidir en la agenda legislativa y en la formación de acuerdos políticos. ${ }^{8}$ Pero el cambio más importante se dio en el plano electoral. Las nuevas normas desvincularon la elección de los órganos subnacionales separándola seis meses de las nacionales. ${ }^{9}$ Además, se instauraron elecciones internas obligatorias para los partidos, donde los ciudadanos voluntariamente pueden votar por los candidatos de los partidos que prefieran. Además, la reforma introdujo el balotaje o segunda vuelta presidencial que debe ser convocada si ninguna de las fórmulas presidenciales ${ }^{10}$ supera la mitad más uno del total de votos emitidos (incluye en blanco y anulados). Ambas medidas, las internas y el balotaje, hicieron que el candidato a presidente y vicepresidente sea apoyado por una clara mayoría del electorado, hecho que no sucedía antes de la aplicación de la norma.

La modificación de la forma de elección de candidatos a la presidencia fue un cambio fundamental respecto del sistema anterior. Antes, los ciudadanos votaban por los partidos o lemas, dentro de él por los sublemas o sectores, cada uno con sus candidatos a presidente. Así resultaba ganadora la fórmula presidencial del sublema más votado dentro del

\footnotetext{
${ }^{8}$ Por ejemplo. cortó los plazos que tenía el Legislativo para el tratamiento de las leyes de urgencia y estableció mayorias especiales para levantar los vetos presidenciales; por lo tanto, concentra algo más de poder en el Ejecutivo. Asimismo, flexibilizó el nombramiento de ministros y secretarios con autorización del Senado, lo que le podría permitir al presidente rediseñar una nueva mayoría en el Parlamento si se quedara en minoria en él, ofreciendo carteras ministeriales a la oposición.

${ }^{9}$ La dimensión local se jerarquiza en esta constitución con la creación de órganos partidarios departamentales, descentralización administrativa y desvinculación de las elecciones nacionales y departamentales.

${ }^{10}$ Cabe aclarar que en Uruguay el presidente se elige en la misma lista con el vicepresidente de la República, por ello se le denomina fórmula electoral.
} 
partido ganador. ${ }^{11}$ De esta manera, el voto popular que tenía cada presidente no superaba en muchos casos el $20 \%$ del electorado, e incluso en ocasiones resultó tener un porcentaje menor a otros candidatos de partidos menos votados $^{12}$ (Tabla 1). Este hecho puede explicar por qué a partir de la elección de 1999 los mandatos comienzan con una luna de miel, hecho que no se registra antes de esta reforma electoral.

Tabla 1. Porcentaje de votos obtenido por la fórmula presidencial ganadora y perdedora 1984-2014

\begin{tabular}{|c|c|c|c|}
\hline & Ganador & Balotaje & $\begin{array}{c}\text { \% Aprobación } \\
\text { presidencial inicial }\end{array}$ \\
\hline 1984 & 31.4 & - & 31.4 \\
\hline 1989 & 38.9 & - & 34.1 \\
\hline 1994 & 24.7 & - & 37.7 \\
\hline 1999 & 40.1 & 54.1 & 56.3 \\
\hline 2004 & 51.7 & - & 69.1 \\
\hline 2009 & 49.3 & 54.6 & 75.3 \\
\hline 2014 & 49.4 & 56.50 & 67.7 \\
\hline
\end{tabular}

Fuente: Resultados electorales sistematizados en Banco de Datos Política y Relaciones Internacionales FCS-UdelaR. "Resultados por fórmula electoral 1971-2009" Votos válidos. En balotaje se reflejan los votos emitidos (para mejorar comparabilidad).

Como muestra la última columna de la Tabla 1, los niveles iniciales de aprobación de los primeros meses de mandato fueron más bajos cuando el caudal electoral de la fórmula presidencial también lo era (antes de la reforma). Esto cambia en los períodos presidenciales posteriores. Allí la apro-

${ }^{11}$ La reforma también eliminó la acumulación por sublemas en los órganos pluripersonales, específicamente elimina el triple voto simultáneo a nivel de diputados, disminuyendo así la cantidad de hojas de votación que se presentan a la elección, pero no la fraccionalización del sistema (Piñeiro, 2004). Sin embargo, se ha señalado que la reforma sí tuvo un efecto reductor de la cantidad de partidos en el sistema al generar un candidato único para todos los sectores y concentrar la competencia en los dos bloques políticos.

${ }^{12}$ Ver datos en Banco de datos Política y Relaciones Internacionales de la Facultad de Ciencias Sociales. Universidad de la República. 
bación es mayor, así como el porcentaje de votos obtenidos por la fórmula presidencial tanto en la primera como en la segunda ronda electoral.

\section{Evolución del sistema de partidos y aprobación presidencial}

El sistema de partidos uruguayo es longevo e institucionalizado, de hecho, los dos principales partidos "fundacionales" o "tradicionales" tienen más de 180 años (Blanco o Nacional y Colorado) y hace casi medio siglo apareció el Frente Amplio (en 1971). Sin embargo, en la historia política reciente, desde $1985,{ }^{13}$ el sistema de partidos ha sufrido una importante transformación. La paulatina disminución del apoyo electoral a los partidos tradicionales (primer y segundo partido hasta 1994) redundó en el aumento del caudal electoral del Frente Amplio, competidor ideológicamente desafiante de los partidos fundacionales. La evolución electoral vista como bloques políticos muestra cómo el subsistema tradicional da paso a una creciente capitalización electoral del Frente Amplio que termina por encontrar su equilibrio en la elección de 2004 (Gráfico 2).

Este reequilibrio del sistema de partidos tuvo su reflejo en la baja de la volatilidad electoral (Tabla 2). Al tiempo que consolidó la lógica de competencia entre dos bloques políticos, uno formado por los partidos fundacionales y el otro por el Frente Amplio. Si se analizan los niveles de aprobación del período y los niveles de volatilidad interpartidaria e interbloque de la elección (Gráficos 3 y 4), no parece existir para el caso de los partidos, pero exceptuando la administración Batlle, si se da una clara relación entre baja volatilidad entre bloques políticos y niveles de aprobación presidencial.

${ }^{13}$ Primera elección después de 12 años de dictadura militar, que comenzó en 1973. 


\section{Gráfico 2. Evolución de las preferencias electorales según partidos/bloques políticos. 1984-2014}

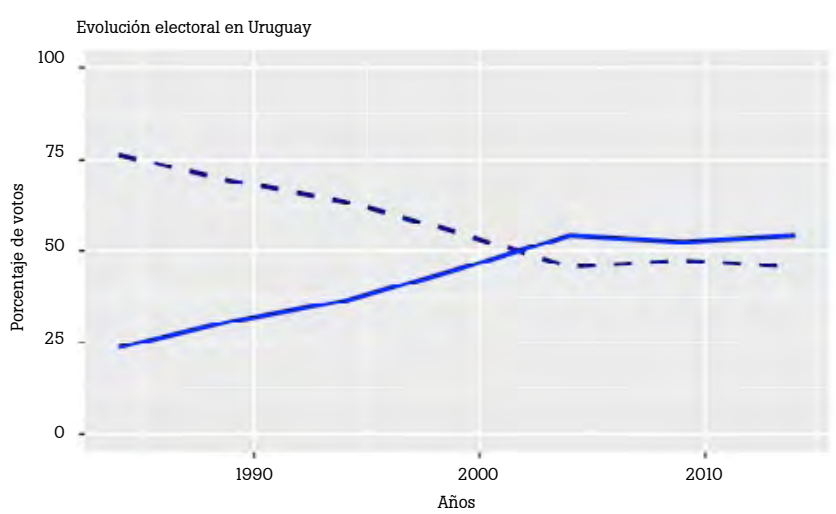

**Referencias: La línea punteada corresponde al apoyo electoral del llamado Bloque Fundacional, compuesto por la sumatoria de los resultados electorales del Partido Nacional y el Partido Colorado. En línea continua el crecimiento electoral del Frente Amplio.*

Fuente: Resultados electorales sistematizados en Banco de Datos Política y Relaciones Internacionales FCS-UdelaR.

\section{Gráfico 3 y 4. Niveles de aprobación presidencial promedio en el período de gobierno y volatilidad interpartidaria e interbloque ${ }^{14}$}

Aprob. presidencial promedio y volatilidad partidos

Aprob. presidencial promedio y volatilidad bloques
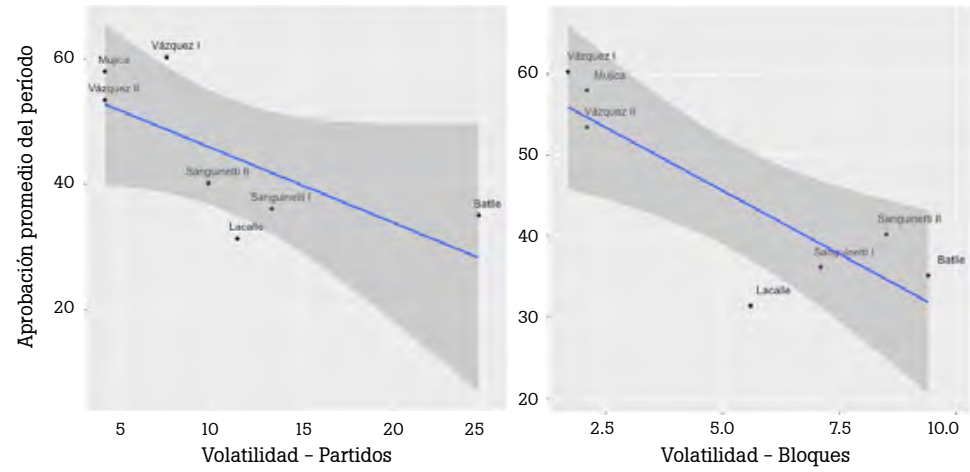

Fuente: Elaboración propia, datos de volatilidad. Los datos de aprobación anual corresponden al Executive Approval Project, periodo 1986-2016, promediados por períodos de gobierno.

${ }^{14}$ Volatilidad entre partidos y bloque: monto de la variación electoral entre partidos políticos y, por otro lado, entre bloques políticos en la elección del periodo 
Tabla 2. Número efectivo de partidos y volatilidad en Uruguay 1984-2014

\begin{tabular}{|llccccccc|}
\hline & & 1984 & 1989 & 1994 & 1999 & 2004 & 2009 & 2014 \\
\hline \multirow{2}{*}{ NEP } & Legislativo & 2,65 & 2,96 & 3,33 & 3,3 & 3,07 & 2,39 & 2,65 \\
\hline \multirow{2}{*}{ Volatilidad } & Partido & 5.7 & 13.4 & 11.5 & 9.9 & 24.8 & 7.6 & 4.2 \\
\cline { 2 - 8 } & Bloque & 4.9 & 7.1 & 5.6 & 8.5 & 9.4 & 1.7 & 2.1 \\
\hline
\end{tabular}

El número efectivo de partidos en diputados fue levemente superior a 2 desde los años 50, pero esto ya estaba cambiando en 1984 (Tabla 3) con un sostenido crecimiento del NEP que supera los 3 puntos. Los principales partidos obtenían dos tercios del electorado, lo que, sumado al peso y autonomía de sus fracciones internas, hacía difícil mantener un acuerdo de gobierno, ya que muchas veces abandonaban unilateralmente las coaliciones partidarias acordadas.

Como efecto de las nuevas normas electorales que se explicaron y la lógica de la competencia política, el número efectivo de partidos disminuyó en el tiempo. Como muestra el Gráfico 5, claramente los niveles de aprobación promedio de las administraciones aumentan conforme disminuye el número efectivo de partidos (NEP). ${ }^{15}$

de gobierno. Elaborado por el Área Política y Relaciones Internacionales del Banco de Datos de la Facultad de Ciencias Sociales - UdelaR.

${ }^{15}$ Excluyendo nuevamente la administración Batlle por las razones ya mencionadas. 
Gráfico 5. Niveles de aprobación presidencial promedio en el período de gobierno y número efectivo de partidos NEP

Aprobación presidencial promedio periodo y NEP

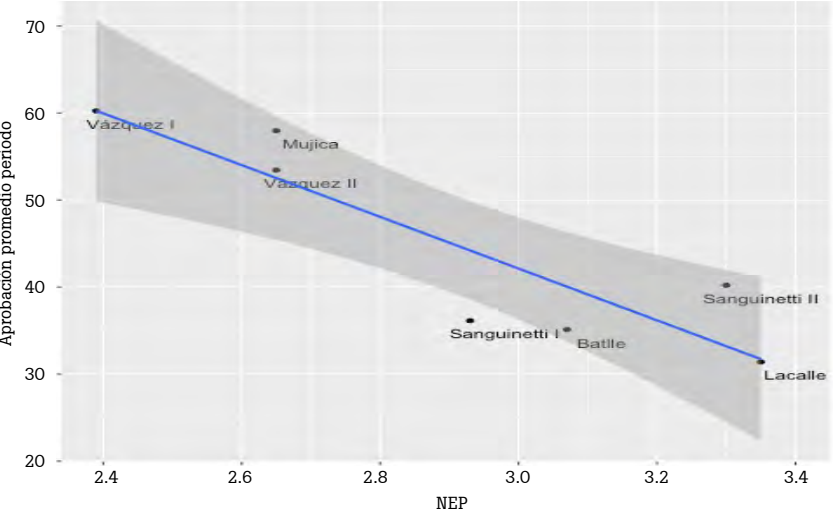

Fuente: Elaboración propia, datos del NEP según la fórmula propuesta por Laasko y Taagepera 1979 - Elaborado por el Área Política y Relaciones Internacionales del Banco de Datos de la Facultad de Ciencias Sociales UdelaR. Los datos de aprobación anual corresponden al Executive Approval Project período 1986-2016 promediados por períodos de gobierno.

\section{Formación de gobierno y aprobación presidencial}

En las últimas décadas se ha asistido a diferentes formas de lograr gobernabilidad en el país. La primera administración de Sanguinetti lo hizo como partido minoritario estableciendo acuerdos puntuales con el Partido Nacional. Durante el siguiente periodo, el Partido Nacional intentó conformar una coalición mayoritaria que duró solo un año, a partir del cual progresivamente sectores colorados y nacionalistas abandonaron el acuerdo, pasando a gobernar con coalición minoritaria hasta el final del mandato. El siguiente gobierno colorado de Julio María Sanguinetti sí logró construir una coalición de mayorias legislativas con el Partido Nacional que duró todo el período. El siguiente gobierno colorado de Jorge Batlle comenzó con una coalición mayoritaria, pero se rompió en torno a la crisis económica de 2002, y terminó su mandato como gobierno minoritario. Los siguientes gobier- 
nos del Frente Amplio fueron gobiernos con mayorías propias en el parlamento. (Chasquetti, 2013: 69).

En materia de aprobación presidencial y gobernabilidad, tal como muestra el Gráfico 6, los niveles de aprobación en el país son mejores en los periodos en los que los gobiernos logran tener la mayoría. La construcción de esas mayorias legislativas se tornó más fácil bajo el nuevo diseño institucional.

\section{Gráfico 6. Niveles de aprobación presidencial trimestrales según} tipo de gobierno en minoría o con mayorías parlamentarias ${ }^{16}$

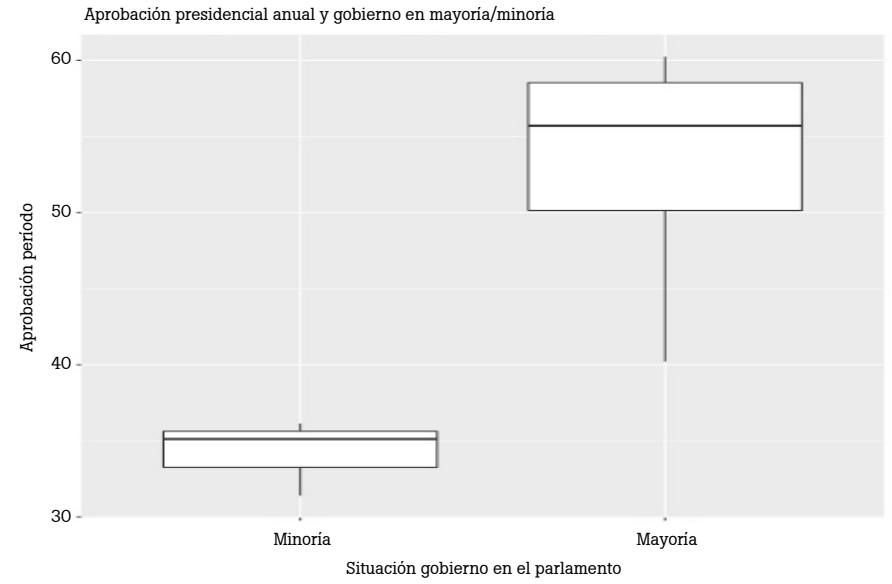

Fuente: Elaboración propia con la distinción entre trimestres con gobiernos con mayorias y gobiernos sin mayorias parlamentarias. Los datos de aprobación trimestral corresponden al Executive Approval Project periodo 1986-2016.

En definitiva, el rápido análisis del caso muestra que las instituciones a partir del año 2000 generaron mayor apoyo popular al presidente y a su vez las instituciones impactaron en los niveles de aprobación presidencial. Especificamente, la aprobación es mayor cuando cambian las normas elec-

\footnotetext{
${ }^{16}$ Mayorias: Si el gobierno gobernó con mayorias parlamentarias propias o coalición. Asume 1 en los trimestres donde el gobierno tenía mayoría y 0 donde no se dieron. El dato es elaboración propia en base Chasquetti, 1998.
} 
torales que exigen al presidente un alto umbral para llegar a ser electo, lo que cambia los niveles iniciales de aprobación. En cuanto al reequilibrio de la competencia política, los datos muestran que en general, para las administraciones posreforma la aprobación es mayor cuanto menor resulta la volatilidad entre bloques, cuantos menos partidos en el sistema y cuando se logra que el presidente tenga mayorías legislativas propias.

\section{Diseño institucional, claridad de la responsabilidad y ciclos de aprobación presidencial}

Un cambio en el diseño institucional está asociado a los patrones de aprobación presidencial a través de su efecto en la claridad de la responsabilidad. Cuando los ciudadanos tienen capacidad de responsabilizar con claridad al ejecutivo, lo evaluarán según sus opiniones respecto de los resultados de las políticas del gobierno, en especial en el ámbito económico (Powell \& Whitten, 1992). Así la "claridad de la responsabilidad" es un concepto que permite entender el mecanismo causal por el cual las instituciones son capaces de afectar la aprobación de los presidentes. La claridad de la responsabilidad afecta tanto al peso que la situación económica tiene sobre la aprobación como en la construcción de las preferencias electorales a partir de la performance durante las administraciones de gobierno e incluso anteriores períodos.

Lamentablemente, la vinculación entre la calidad de la responsabilidad y el cambio institucional se presenta aquí como un supuesto teórico, pues se carece de series de tiempo lo suficientemente largas como para comprobar a través de actitudes individuales ${ }^{17}$ si los ciudadanos efectivamente responsabilizan más o menos al presidente antes y después de los cambios institucionales en Uruguay. Por esta razón no

\footnotetext{
${ }^{17}$ Las preguntas sobre quién es el principal responsable de los problemas del pais, específicamente en qué medida el presidente es responsable, que están disponibles en Latinobarómetro o Lapop, no cubren los dos períodos que se pretende estudiar.
} 
se ha ahondado en el análisis empírico de este supuesto, pero se suple con la amplia evidencia de otros trabajos que comprueban este fenómeno (Rudolph, 2003; León, 2010; Renoò \& Garmacho, 2010).

Asumiendo, entonces, esa conexión entre instituciones y claridad de la responsabilidad, corresponde preguntarse cómo la claridad de responsabilizar puede llevar a que la dinámica de aprobación presidencial adopte un modelo cíclico. Si las instituciones otorgan mayor respaldo popular al presidente, este comenzará su mandato con el fenómeno denominado "luna de miel" asociado a la cantidad de votos recibidos, pero también a la esperanza que los ciudadanos depositan en un nuevo gobierno (Carlin et al., 2018). La evolución de la aprobación en el periodo se ciñe al ciclo político marcado por el carácter acotado del período presidencial y es determinada por las evaluaciones ciudadanas sobre los resultados en diferentes áreas de políticas, especialmente en materia económica. Así, a la mitad del mandato se espera una baja de la aprobación, debido a que los gobiernos se permiten adoptar políticas restrictivas. De la misma manera, la magnitud del aumento de la aprobación hacia el final del periodo depende nuevamente del ciclo político, ya que se asocia a la proximidad de las elecciones (Stimson, 1991) y a las políticas que el presidente promueve para aumentar la probabilidad de que su partido sea reelecto (ver, por ejemplo, Berlemann \& Enelkemann, 2012).

La literatura resalta dos causas principales de la aprobación presidencial mediante la claridad de responsabilidad: los resultados/outputs, por un lado, y contextos, por otro. Algunos trabajos que se centran en los resultados señalan que son los efectos de las políticas implementadas los que impactan en la dinámica de aprobación. En particular, la aprobación depende de los resultados económicos, así como los resultados de política internacional (McAllister, 1999; Sarin \& Villalobos, 2011; Samuels, 2004) e incluso la declaración de guerra a terceros paises en el caso de EE.UU. (Mueller, 1973; Powell \& Whitten, 1992:411). Otras investi- 
gaciones señalan que la aprobación es sensible a problemas puntuales de alta visibilidad como escándalos políticos o de corrupción (Mueller, 1970) y actos de violencia (Booth \& Seligson, 2009; Carlin et al., 2015b; Newman \& Forcheimes, 2008; Tavits, 2007). ${ }^{18}$

Los que consideran el contexto argumentan que la identificación de la responsabilidad y su impacto en la evaluación presidencial está condicionada por las capacidades que tenga el presidente para controlar la agenda política. Estas capacidades, a su vez, vienen dadas por aspectos institucionales tales como los poderes que el presidente tiene respecto del parlamento y del gabinete ministerial, el número de partidos y su peso en el parlamento. (Martínez-Gallardo, 2001; Calvo, 2007; Carlin et al., 2015 a y b; Rennó $\&$ Gramacho, 2010). En la misma, línea otros estudios alertan sobre otras capacidades del presidente, por ejemplo, la forma en que maneja convincentemente las narrativas sobre las políticas y los problemas del país (Stokes, 2001 ; Carlin et al., 2015a; Gramacho, 2005), narrativas que, a su vez, dependen del papel que juegan los medios de comunicación (Pérez-Liñán, 2007) al alterar o reforzar la claridad con la que la ciudadanía responsabiliza al presidente.

Este artículo adhiere a la idea de que los resultados u outputs importan, pero su impacto depende del contexto institucional y político, ya que este es el que permite mayor o menor claridad de responsabilidad. Si existe claridad para responsabilizar, el peso de los resultados, en especial los económicos, resultará fundamental para entender los cambios en el apoyo presidencial. Según la teoría del voto económico, el ciudadano es un individuo racional que tendrá en cuenta los resultados para evaluar lo hecho por

\footnotetext{
${ }^{18}$ En Uruguay los casos de corrupción y escándalos que involucren al Ejecutivo no han sido relevantes en el periodo estudiado. De hecho, los índices internacionales lo destacan como un caso con bajos niveles de corrupción y no se encuentran escándalos que involucren a los presidentes de estas administraciones (Carlin et al., 2015 b). Por su parte, en cuanto a la politica exterior, dado el tamaño económico y político del país sus posturas no repercuten en la opinión pública.
} 
el gobierno, desaprobarlo $\mathrm{y}$, eventualmente, cambiarlo en la siguiente elección (Key, 1968; Dalton, 2000; Anderson, 2000). De esta manera, la evaluación de la gestión y la decisión electoral se basan en la evaluación de resultados premiando o castigando al incumbent según su desempeño en materia económica. El análisis se puede basar en las percepciones prospectivas o retrospectivas de los individuos (Fiorina, 1981) o en la relación a nivel agregado bajo la perspectiva de "Macro Polity" (Erickson, MacKuen, \& Stimson, 2002).

Tal como se explica en la Ilustración 1, si los ciudadanos son capaces de responsabilizar a su presidente por los resultados del gobierno en materia económica, esos serán los predictores más importantes de los niveles de aprobación (Powell \& Whitten, 1992). Bajo esta lógica, la dinámica cíclica de la aprobación va a estar condicionada por las medidas restrictivas y menos populares que los gobiernos adoptan hacia mitad del mandato, así como de políticas expansivas en la última etapa de su periodo de gobierno (Berlemann \& Enelkemann, 2012; Stimson, 1991).

\section{Ilustración 1. Mecanismo causal, instituciones, contexto y aprobación presidencial I}

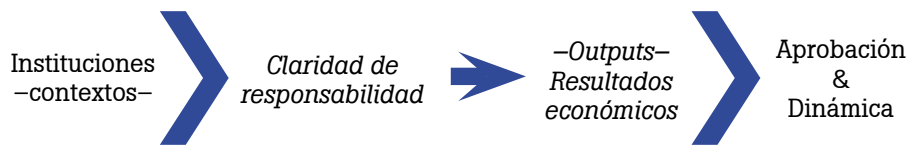

Las instituciones entonces pueden generar mayor claridad de responsabilidad y esta, a su vez, otorgar mayor peso al resultado económico en los niveles de aprobación. Pero también es cierto que al final del período los ciudadanos apoyarán o castigarán electoralmente al partido en el gobierno según los resultados obtenidos durante el período (Key, 1968; Dalton, 2000; Anderson, 2000). De esta manera, la decisión de voto depende de repetidas evaluaciones de lo hecho por el gobierno durante su administración (Ilustración 2) e incluso de anteriores administraciones. Varios estudios advier- 
ten que aquellos ciudadanos que piensan votar al partido del presidente evalúan su gestión de manera mucho más favorable que aquellos que no tienen una preferencia política definida (Dalton, 2000; Cabezas, 2015; Lebo \& Cassino, 2007). Si los resultados refuerzan preferencias políticas, es posible que la dinámica no responda tanto a los resultados de las políticas económicas del gobierno, sino al ciclo político-electoral donde se da mayor involucramiento e interés ciudadano al inicio y final de los mandatos con mayor apatía y desinterés a la mitad del período (Goodhart \& Bhansali, 1970).

Ilustración 2. Mecanismo causal, instituciones, contexto y aprobación presidencial II

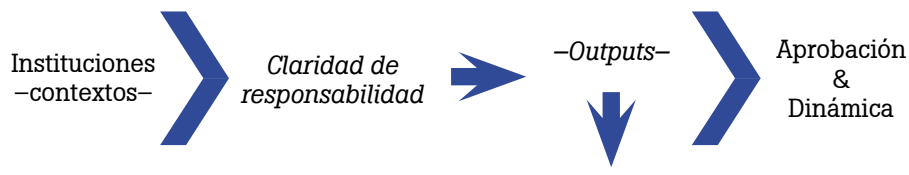

Apoyo electoral

Ambos fenómenos, performance económica y preferencia electoral, ofrecen explicaciones empíricamente vinculadas y lógicamente alternativas de la aprobación presidencial. Teniendo muy presente que a nivel individual es difícil separar los efectos sobre la evaluación presidencial de la situación económica y el apoyo electoral del presidente, en el análisis agregado sí es posible hacerlo. A este nivel existe una diferencia conceptual dada por el origen y el efecto temporal de cada una de estas variables, tanto que a este nivel supera la prueba de colinealidad con la evaluación presidencial (ver Tabla 4 en el siguiente apartado). Es posible entonces sostener que a nivel agregado, el efecto que tienen los resultados económicos sobre la aprobación es reactivo e inmediato mientras que el efecto del voto es estructural y de largo plazo, sobre todo cuando las preferencias electorales son estables y el número de partidos, reducido (Holmberg, 2009; Huber et al., 2005). 
Los trabajos previos sobre la temática en Uruguay coinciden en que las variables económicas son predictores importantes de la evaluación presidencial. Pero, considerando que los niveles y la dinámica de aprobación cambiaron a partir del año 2000, tiene sentido pensar que las nuevas instituciones modificaron la claridad de la responsabilidad. $\mathrm{El}$ aumento en la claridad, a su vez, hace más relevante el efecto de las políticas, principalmente económicas, en este período que en el anterior.

Para entender los cambios en la dinámica de la aprobación presidencial, este trabajo vincula empiricamente el impacto de los cambios en el diseño institucional y en la dinámica de aprobación, comparando el comportamiento de los indicadores económicos en ambos contextos institucionales (antes y después de los cambios). Se espera encontrar que, al existir mayor claridad de responsabilidad, mayor será el peso de los indicadores económicos, otorgando a la serie su dinámica cíclica.

Hipótesis: Con posterioridad a la reforma, los predictores económicos aumentan su relevancia sobre la evaluación de la gestión presidencial, explicando los ciclos de aprobación.

Alternativamente, se puede pensar que, dadas las instituciones y el reequilibrio en el sistema de partidos, las preferencias electorales, asociadas a largo plazo a los outputs, sean las que estén pautando este nuevo patrón cíclico de la aprobación presidencial, asociado al ciclo electoral.

Hipótesis Alternativa: En el momento posterior a la reforma, las identificaciones partidarias impactan de mayor manera en la evaluación de los presidentes, explicando los ciclos de aprobación.

A la hora de analizar la evolución en la aprobación en Uruguay, conviene tener presente que pueden influir dos circunstancias que operarán en este trabajo como variables de control. Una asociada al desgaste del gobierno o timing, que controla tanto el desgaste de los líderes como la existencia a mitad de mandato de otras políticas (no necesariamente económicas), cuyos resultados no fueran los esperados por la ciudadanía. 
La otra son las iniciativas de democracia directa. Estas iniciativas pueden impactar sobre la evaluación de la gestión (Luna, 2002; Altman, 2010), ya que a través de ellas se establece un mecanismo alternativo para expresarse sobre una política implementada por el gobierno. Es, en definitiva, una forma de expresar descontento, por lo que cabe esperar que también altere la evaluación presidencial (Boelhower, 2018; Luna, 2002). En el caso uruguayo, los mecanismos de democracia directa que apuntan a derogar leyes (referéndums) y las que modifican la constitución (plebiscitos) han sido habituales en la historia reciente. Estas iniciativas fueron muy frecuentes, apoyadas por la oposición y mayormente exitosas en las tres administraciones de gobierno que no siguen un modelo cíclico de aprobación pero que, luego del 2000, han disminuido y no han contado con el apoyo mayoritario de la ciudadanía.

Cabe justificar tres ausencias importantes del modelo que se propone analizar. Por un lado, no se considera el contexto económico favorable ("boom de las commodities") en el que transcurren las administraciones con patrón de evaluación cíclica, ya que se incluye el análisis bivariado de los niveles de aprobación y el crecimiento del PIB sin que arroje resultados significativos (Ver Anexo). Por su parte, el hecho de que las administraciones del Frente Amplio hayan gobernado con mayorias propias y el de Batlle con una coalición amplia antes de la crisis económica que se dio en su administración no asume casi variación intraperiodos, ya que luego del cambio institucional en casi todos los períodos se gobernó en mayoría y antes en minoría. Finalmente, la orientación ideológica del gobierno tampoco fue incluida, ya que antes del 2005 todas las administraciones fueron de centro-derecha y a partir de ese año hasta 2015 de centroizquierda. Dicho de otra manera, antes de la reforma no hay variación y luego hay una administración de centro-derecha y tres de centro-izquierda, que no brindaba importante variabilidad, no afectaba los resultados y restaba robustez a los modelos propuestos. 


\section{Métodos y datos}

El siguiente análisis se basa en datos trimestrales (smoothing) de aprobación presidencial sistematizados por el Executive Approval Project ${ }^{19}$ como variable dependiente. Los indicadores de la situación económica (VI) se podían basar en las percepciones prospectivas o retrospectivas de los individuos (Fiorina, 1981) o en la relación a nivel agregado bajo la perspectiva de "Macro Polity" (Erickson, MacKuen, \& Stimson, 2002). Puesto que no se cuenta con series individuales lo suficientemente largas, se opta por la segunda estrategia, utilizando datos de indicadores económicos trimestrales de desempleo e inflación del Instituto Nacional de Estadística ${ }^{20}$ y Producto Interno Bruto del Banco Central del Uruguay. ${ }^{21}$ Por su parte, para el apoyo electoral al presidente se trabaja con el porcentaje de intención de voto al partido del presidente registrado por la consultora Equipos Mori. ${ }^{22}$ Las variables de control son el tiempo transcurrido desde que asumió el gobierno, medido en trimestres, una variable dicotómica que indica la ocurrencia de instancias de democracia directa en el trimestre observado.

La estrategia analítica consistió en la creación de dos cortes temporales con el objeto de observar si cambia el peso de las variables dependientes sobre los niveles de aprobación en uno y otro contexto a través de modelos de regresión ADL (Autoregressive Distributed Lag). Estos modelos de regresión estocásticos permiten analizar los predictores según tendencia (trend) y estacionalidad (seasonal) y aleatorios (random) y superan los problemas de autocorrelación asociados a las series temporales en otros modelos de regresión (Ver gráfico 7).

\footnotetext{
${ }^{19}$ Periodo 1986 tercer trimestre hasta el 2016 segundo trimestre.

${ }^{20}$ Sistematizados por el Área Sociodemográfica del Banco de Datos de la Facultad de Ciencias Sociales, Universidad de la República. Datos disponibles para todo el período.

${ }^{21}$ Obtenidos gracias al Área Económica del Banco de Datos de la Facultad de Ciencias Sociales.

${ }^{22}$ Disponible desde el segundo semestre de 1989 cubriendo solo seis meses del primer gobierno de Sanguinetti.
} 
A través de la construcción de los modelos es posible observar la magnitud y significación estadística (a dos colas) de las variables independientes antes y después de la reforma, incluyendo o excluyendo la intención de voto en el análisis, para observar cómo operaron los contextos económico y político sobre la aprobación presidencial. Por último, y con el fin de explorar el peso relativo de cada variable sobre la aprobación presidencial en general y en diferentes contextos, se presenta la tabla con los coeficientes betas y su significación.

Gráfico 7. Descomposición aditiva de la serie temporal evaluación trimestral ${ }^{23}$

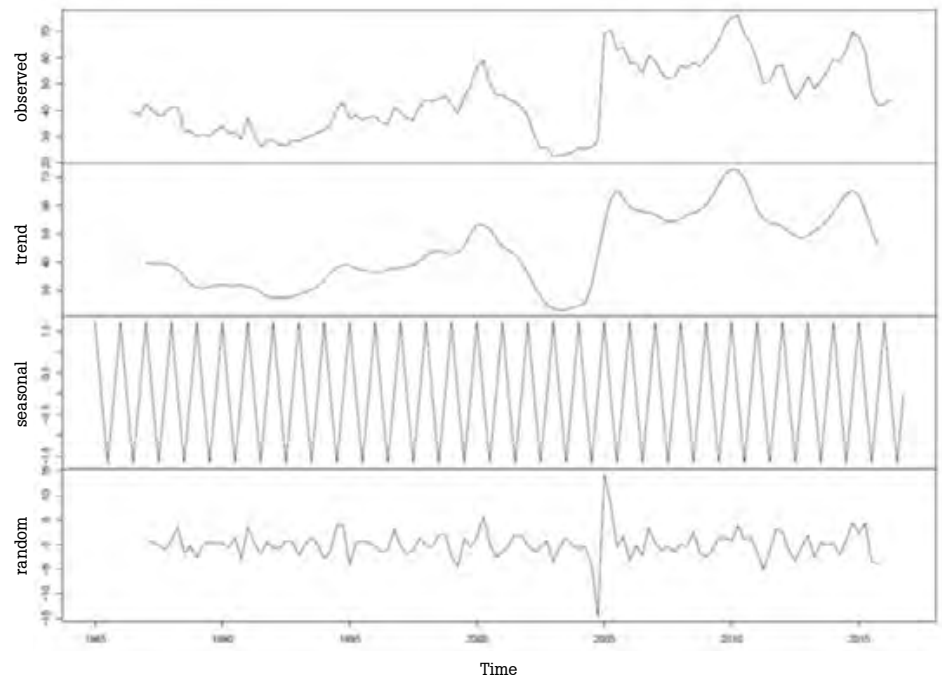

En la especificación de los modelos, de las variables económicas han sido lageadas: se ha retardado su efecto. De esta manera, la aprobación es una reacción a la variación del

${ }^{23}$ Los bajísimos niveles de aprobación de la tendencia en el año 2002 se corresponden a los peores momentos de una grave crisis económica y financiera que transitó el país. El pico del año 2005 en los efectos random corresponde al cambio de gobierno luego de la crisis y primer gobierno del Frente Amplio. 
indicador económico en el trimestre anterior. Lo mismo sucede con el porcentaje de voto al partido del presidente. El apoyo en el trimestre anterior o en el tiempo t-1 será relevante para explicar la aprobación en el siguiente trimestre. Las otras variables introducidas en el modelo no fueron retardadas por considerar que su efecto es concurrente con el nivel de aprobación. Esto se aplica para el caso del tiempo de gobierno o timing y consultas de democracia directa. En otras palabras, si existen causas asociadas al desgaste en el gobierno, su impacto se registra de manera conjunta, igual que la celebración de una consulta popular como plebiscito o referéndum.

Tabla 4. Matriz de correlaciones y test de colinealidad (Variables temporales)

\begin{tabular}{|c|c|c|c|c|c|c|}
\hline & Inflación & Desempleo & Crecimiento & $\begin{array}{c}\% \\
\text { intención } \\
\text { voto al } \\
\text { partido del } \\
\text { Presidente }\end{array}$ & $\begin{array}{l}\text { Tiempo } \\
\text { de } \\
\text { gobierno }\end{array}$ & $\begin{array}{l}\text { Demo } \\
\text { Direc- } \\
\text { ta }\end{array}$ \\
\hline Inflación & 1 & $-0,21$ & $-0,64$ & $-0,32$ & $-0,05$ & 0,04 \\
\hline Desempleo & $-0,21$ & 1 & 0 & $-0,03$ & $-0,10$ & $-0,02$ \\
\hline Crecimiento & $-0,64$ & 0 & 1 & 0,30 & $-0,01$ & 0,00 \\
\hline $\begin{array}{l}\text { \% intención } \\
\text { de voto al } \\
\text { partido del } \\
\text { Presidente }\end{array}$ & $-0,32$ & $-0,03$ & 0,30 & 1 & 0,08 & $-0,08$ \\
\hline $\begin{array}{l}\text { Tiempo de } \\
\text { Gobierno }\end{array}$ & $-0,05$ & $-0,10$ & $-0,01$ & 0,08 & 1 & 0,38 \\
\hline $\begin{array}{l}\text { Demo } \\
\text { Directa }\end{array}$ & 0,04 & $-0,02$ & 0,00 & $-0,08$ & 0,38 & 1 \\
\hline $\begin{array}{l}\text { Test Inflación } \\
\text { de varianza } \\
\text { (FIV) }\end{array}$ & 3,62 & 2,60 & 4,27 & 1,16 & 1,28 & 1,21 \\
\hline $\begin{array}{l}\text { Test Inflación } \\
\text { de varianza } \\
\text { (FIV) } \\
\text { Sin PIB }\end{array}$ & 1,18 & -- & 1,07 & 1,14 & 1,20 & 1,19 \\
\hline
\end{tabular}


Por otro lado, cabe señalar que, para construir los modelos, se eliminó la variable de crecimiento porque presentaba una fuerte colinealidad (Tabla 4) llegando a más de 4 puntos en el test de inflación de varianza (FIV), y porque la teoría prioriza el desempleo y la inflación, siendo estos mejores predictores de la aprobación en el país (Luna, 2002). Sin esta variable, el test FIV muestra niveles aceptables para evitar la colinealidad entre las variables introducidas en el modelo.

La tabla muestra la débil asociación entre voto y tiempo en el gobierno y la baja relación entre voto e indicadores económicos, lo que apoya la idea del largo y corto plazo problematizada en el apartado anterior, que sustenta la decisión de separar su impacto en este análisis.

\section{Análisis}

Diversos estudios señalan que la economía ha sido la principal explicación de los niveles de aprobación presidencial en Uruguay. Si bien no se ha indagado la hipótesis alternativa sobre preferencias electorales ni controlado los efectos de tendencia, estacionalidad y aleatorios que alteran los posibles hallazgos de series temporales, tampoco se ha visto qué sucedió con los indicadores bajo los dos contextos institucionales identificados. Considerando que en el país se produjo un cambio en las instituciones que afecta la claridad de responsabilizar junto a un cambio en la dinámica de aprobación, resulta imprescindible analizar su comportamiento en ambos momentos.

El primer ejercicio analítico consiste en el tratamiento bivariado de los indicadores, para observar su comportamiento en los dos contextos. Los resultados que se encuentran en el Anexo indican que el crecimiento del PIB siempre tiende a aumentar la aprobación trimestral, por lo que la bonanza económica de los últimos años no parecería alterar la relación. Sin embargo, la inflación sí marca un comportamiento distinto en cada uno de los contextos. Antes de los 
cambios institucionales, el crecimiento del IPC se relacionaba más acentuadamente con los niveles de aprobación que en el período posterior. Por su parte, el desempleo aparece asociado a la aprobación en los momentos posteriores al cambio institucional y, llamativamente, correlacionaba de manera inversa bajo las viejas instituciones: a mayor desempleo, mayor aprobación presidencial. ${ }^{24}$ Finalmente, la intención de voto al partido del presidente aparece como predictor casi perfecto solo bajo el nuevo contexto institucional, siendo irrelevante en el contexto institucional anterior.

La regresión bivariada ayuda a ilustrar la incidencia individual de cada indicador, pero puede esconder relaciones espurias que no permiten ver el impacto real de las variables sobre la aprobación presidencial. Como se justificó antes, el PIB fue eliminado del análisis y además se incluyeron otras variables de control. A continuación se presentan los resultados de 4 modelos de regresión ADL. El gráfico de la izquierda contiene los modelos antes de la reforma institucional y el de la derecha los de después. En cada uno de ellos se presentan dos modelos: uno muestra los coeficientes y la desviación estándar de las variables económicas, controlados por variables de desgaste político y democracia directa. Y en el otro se agrega el porcentaje de intención de voto al partido en el gobierno cumpliendo con la hipótesis alternativa propuesta.

Bajo el viejo contexto institucional (lado izquierdo) se observa que la inflación es la variable que tiene mayor impacto en los niveles de aprobación. En este período, a mayor inflación, menor nivel de aprobación. Tal como se podía prever del análisis bivariado, el desempleo no aparece como un buen predictor de la evolución de la evaluación presidencial. Otro hallazgo que coincide con estudios pre-

\footnotetext{
${ }^{24}$ Los datos tratados no coinciden del todo con hallazgos previos; sin embargo, la analítica empleada lageada, muestra que, en ese período, a mayor desempleo, mayor la aprobación presidencial. Lo que se revierte bajo el nuevo contexto institucional. Tal vez la falta de claridad para responsabilizar pueda ser, en el período anterior, una forma de explicar este extraño hallazgo.
} 
vios es que los niveles de aprobación en este período son afectados por instancias de democracia directa, pero en este caso aumentando el nivel de aprobación presidencial. Finalmente, cuando el modelo es controlado por intención de voto, no se alteran los resultados y, claramente, preferencia electoral y timing político resultan variables insignificantes para explicar las variaciones en los niveles de aprobación presidencial bajo el viejo contexto institucional.

Gráfico 12. Modelos antes después con y sin intención de voto al partido en el gobierno sobre la aprobación presidencial antes después del cambio institucional

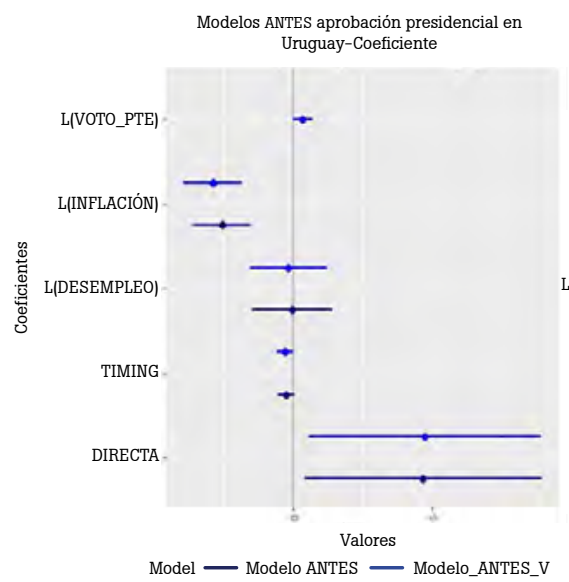

Modelos DESPUÉS aprobación presidencial en Uruguay-Coeficiente

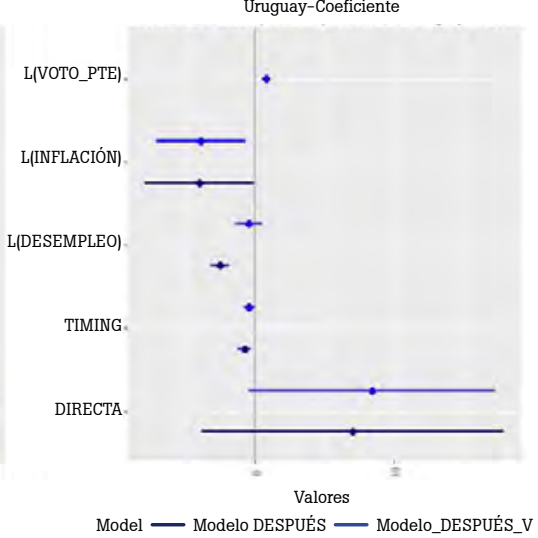

En los modelos posteriores al cambio institucional (en el gráfico, del lado derecho), los resultados muestran que, sin considerar la intención de voto, la inflación no se relaciona con la aprobación presidencial ni tampoco las instancias de democracia directa. Este modelo muestra que la variación de la aprobación viene pautada por la variación en el desempleo y el timing del ciclo político. Sin embargo, cuando se incluye la intención de voto, la incidencia de las variables cambia. En este caso, la variable de intención de voto, conjuntamente con la inflación, resultan unos buenos predictores. Con este control por intención de voto, el timing y 
el peso del desempleo desaparecen como predictores de los cambios en la evaluación de la gestión presidencial.

En resumen, los resultados indican que antes de los cambios institucionales, la aprobación estaba sujeta a la inflación, política menos controlada por los gobiernos de los países como el Uruguay con su economía sujeta a variaciones externas de tipo de cambios y precios internacionales. Sin embargo, las variables que sí podrian ser relacionadas a la responsabilidad directa del gobierno (como políticas de desempleo) o incluso el timing político no tuvieron incidencia alguna. Tal vez, la aparición de las instancias de democracia directa, que fueron frecuentemente impulsadas en ese período por la oposición al gobierno, hacía centrar la atención en el presidente, que solía ser la figura que concentraba la defensa de la ley que se pretendía modificar. En este contexto de preferencias electorales que venian cambiando, junto a la existencia de múltiples candidaturas por partido y socios de coalición, la intención de voto no se asociaba a la evaluación presidencial.

Pero entonces, ¿por qué cambió la dinámica de aprobación en Uruguay adoptando después del cambio institucional un modelo cíclico de aprobación?

Posteriormente a la reforma, los resultados muestran mayores variables asociadas a la evolución de la aprobación presidencial, tanto la incidencia del desempleo como el timing político justifican la adopción cíclica de la serie de aprobación, centrada en los outputs o resultados de la gestión. Alternativamente, si se considera la intención de voto junto a la incidencia de la inflación, también permite pensar que el ciclo puede estar pautado por el ciclo electoral, con mayor apoyo al inicio y final del mandato y sujeto a descontentos e indecisión en la mitad del periodo. Evidentemente, las nuevas reglas electorales y la estabilización de la competencia política pueden justificar esta forma de pensar la dinámica cíclica de aprobación.

En definitiva, tal como se planteaba en las hipótesis, los modelos muestran que la incidencia de las políticas eco- 
nómicas de mayor control del gobierno, tiempos políticos y electorales aumentan bajo el nuevo contexto electoral.

\section{Lo que el caso nos dejó y nos depara...}

Las series de aprobación presidencial en el Uruguay desde la reapertura democrática han ido cambiando. Junto a los cambios institucionales introducidos en la Constitución de 1997 y al nuevo equilibrio del sistema de partidos, las series aumentaron su promedio y los patrones de evaluación se volvieron cíclicos por el peso que la evaluación de resultados económicos, timing de gobierno y ciclo electoral adquirieron luego de estos cambios institucionales.

Según la evidencia presentada, el cambio de reglas electorales en Uruguay ha conseguido que los ciudadanos tengan mayor claridad a la hora de responsabilizar al Ejecutivo respecto de los resultados de las políticas llevadas a cabo en su gobierno (Powell y Whitten, 1992). El cambio en las normativas electorales y la estabilización de la competencia en Uruguay otorgó mayor "claridad de responsabilidad" a los ciudadanos y, por lo tanto, la variación en los predictores de aprobación nos permite entender el mecanismo causal por el cual la dinámica de aprobación se volvió cíclica.

En el caso uruguayo, la aparición de la luna de miel, sostenida en el amplio apoyo electoral que a partir de la reforma requiere el candidato a la presidencia, junto con la disminución de veto players y el control de las mayorías en el parlamento permite una mayor identificación inicial de los ciudadanos con el presidente, y sobre todo una buena claridad para responsabilizarlo por la marcha del país. Así los resultados de las políticas económicas y el timing político electoral generan el típico modelo cíclico de aprobación característico de los sistemas presidencialistas. El análisis también deja puertas abiertas para futuras investigaciones. En materia económica, por ejemplo, los hallazgos permiten pensar en qué medida la inflación, en un contexto de país de economía dependiente, puede ser vinculada a un ciclo 
de políticas totalmente controladas por el gobierno, lo que permite reflexionar sobre la conveniencia de aplicar la idea del voto económico y claridad de la responsabilidad en el contexto de países en vías de desarrollo. Pero también es honesto resaltar que, si bien tanto el crecimiento del desempleo como la inflación han estado siempre asociados a la evaluación de gestión, para el caso estudiado, el "boom de las commodities" y la época de bonanza permitió a los últimos gobiernos mantener una política monetaria menos fluctuante y atraer inversiones al país, lo que generó mayor control de precios y disminuyó el desempleo.

Otro hallazgo del trabajo señala la importancia de la estabilidad de las preferencias partidarias como resultado de evaluaciones acumuladas, menos volátiles, que ofrecen una alternativa explicativa a los ciclos de aprobación, más vinculada a identidades políticas que a resultados de políticas en el corto plazo. Cabe problematizar la relación entre la aprobación y la ideología del gobierno. Powell \& Whitten (404: 1992) sostienen que el desempleo es un predictor más gravitante para evaluar la performance de los gobiernos de izquierda y el control de la inflación para los de derecha. Si bien esta afirmación puede dejar una ventana abierta para futuras investigaciones, es cierto que, cuando predominaban los gobiernos de izquierda (posreforma), la inflación no desaparece del todo en los modelos. Y que antes, con gobiernos de centro-derecha, el desempleo encabezaba la lista de los problemas más importantes del país. ${ }^{25}$ Por lo que no parece como la explicación razonable a lo sucedido en el país; por el contrario, tal como se ha mostrado, los cambios de los predictores de aprobación presidencial han sido modificados por los contextos institucionales, asociado a una mayor responsabilización de la ciudadanía por resultados económicos en general, timing y ciclo electoral. No por las políticas que la ciudadanía espera según la orientación ideológica del gobierno.

${ }^{25}$ Ver datos en Latinobarometro.org. Principal problema del pais. 
Este artículo se termina de escribir en los albores de la campaña electoral de 2019 y en el fin de la era del boom de las commodities. Los analistas sostienen que el próximo gobierno deberá formar coaliciones para obtener mayorias legislativas, en condiciones económicas internacionales menos favorables. Estas dos condiciones, el fin de la bonanza económica y posibles cambios en la forma de gobernar, pueden alterar muchas cosas, pero probablemente no la claridad de la responsabilidad que los ciudadanos tienen para con el presidente, debido a la normativa electoral vigente, que le permitirá contar con su luna de miel y ser responsable ante todos los socios de la coalición. A los próximos presidentes bajo este contexto institucional les será difícil diluir responsabilidades ante resultados económicos y el timing de gobierno y ciclo electoral probablemente seguirán marcando el patrón cíclico de la aprobación presidencial en Uruguay.

\section{Referencias}

Altman, D. (2010). Direct Democracy Worldwide. Cambridge: Cambridge University Press.

Anderson, C. J. (2000). "Economic Voting and Political Context: A Comparative Perspective". En: Electoral Studies, 19, 151-170.

Anderson, C. J. (2007). "The End of Economic Voting? Contingency Dilemmas and the Limits of Democratic Accountability". Annual Review of Political Science, 10, pp. 271-296.

Berlemann, M. \& S. Enkelmann (2012). "The Economic Determinants of U.S. Presidential Approval - A Survey". Working Paper Series in Economics 272, University of Luneburg, Institute of Economics, 2012.

Boelhower, D. (2018). "Aprovação presidencial (1996-2015) na América Latina: mais participação pode ser uma saída quando a economía vai mal". Em: Revista de Ciências Sociais (UFC) no Dossiê Os Significados das Novas Quedas Presidenciais na América Latina, Vol. 49, Nº 1, pp. 134-165. 
Booth J. A. \& M. A. Seligson (2009). The Legitimacy Puzzle in Latin America: Political Support and Democracy in Eight Nations. New York: Cambridge University Press.

Buquet, D. \& R. Piñeiro (2014). "La consolidación de un nuevo sistema de partidos en Uruguay - The Consolidation of a New Party System in Uruguay". Debates. 8. 127-148.

Butler D. \& D. Stokes (1969). Political change in Britain. St. Martin's Press, 1971.

Cabezas, J. M. (2015). "Aprobación presidencial en América Latina, 2010- 2012. Voto Económico y preferencias políticas". Política. Revista de Ciencia Política. Vol. 53, No 1, 2015. p. 15-35.

Calvo, E. (2007). "The Responsive Legislature: Public Opinion and Law Making in a Highly Disciplined Legislature". British Journal in Political Studies, 37(2), 263-280.

Carlin, Ryan E., Jonathan Hartlyn, Timothy Hellwig, Gregory J. Love, Cecilia Martínez-Gallardo, \& Matthew M. Singer. "Public Support for Latin American Presidents: The Cyclical Model in Comparative Perspective". Research \& Politics, Vol. 5, Issue 3, July 1, 2018. https://doi.org/10.1177/2053168018787690.

Carlin R., G. Love \& C. Martínez-Gallardo (2015a). "Security, Clarity of Responsibility, and Presidential Approval. In: Comparative Political Studies, Vol. 48, DOI: 10.1177/0010414014554693.

Carlin R. E., Gregory J. Love \& Cecilia Martínez-Gallardo (2015b). "Cushioning the Fall: Scandals, Economic Conditions, and Executive Approval." Political Behavior DOI 10.1007/s11109-0149267-3.

Carlin R., C. Martínez-Gallardo, \& J. Hartlyn (2012). "Executive Approval Dynamics under Alternative Democratic Regime Types". In: Douglas Chalmers \& Scott Mainwaring (eds.) Problems Confronting Contemporary Democracies: Essays in Honor of Alfred Stepan. South Bend: University of Notre Dame Press.

Carlin, R. \& K. H. Hunt (2015). "Peasants, Bankers, or Piggbankers? The Economy and Presidential Popularity in Uruguay". Politica. Revista de Ciencia Política. Vol. 53, N 1, pp. 73-93.

Chasquetti, D. (1998). "Compartiendo el gobierno: multipartidismo y coaliciones en el Uruguay (1971-1997)". En: Revista Uruguaya de Ciencia Política, $\mathrm{N}^{\circ} 10$ (25-45). 
Chasquetti, D. (2013). "Cabinets and Legislative Cartels in Uruguay: Examining the Legislative Consequences of Government Formation" Journal of Politics in Latin America, 5(1), 67-94.

Dalton, R. (2000). "The Decline of Party Identification". In: Russell J. Dalton \& Martin P. Wattenberg (eds.) Parties without Partisans: Political Change in Advanced Industrial Democracies. Oxford, UK: Oxford University Press.

Erikson, Robert. S., M. MacKuen, \& J. A. Stimson (2002). The Macro Polity. New York: Cambridge University Press.

Fiorina, M. P. (1981). Retrospective Voting in American National Elections. New Haven: Yale University Press.

Gramacho, W (2005). "Ciclos de información y funciones de popularidad: El periodo Cardoso en Brasil (1995-2002)". Desarrollo Económico, Vol. 45, № 177, 2005, pp. 99-121.

Goodhart, C.A. E. \& R. J. Bhansali (1970). "Political economy". Political Studies 18, PP. 43-106

Holmberg, S. (2009). "Partisanship Reconsidered". The Oxford Handbook of Political Behavior. 557-570. 10.1093/oxford$\mathrm{hb} / 9780199270125.003 .0029$.

Huber, John D., G. Kernell, \& E. L. Leoni (2005). "Institutional Context, Cognitive Resources and Party Attachments across Democracies". Political Analysis [online]. No date, Vol. 13, $\mathrm{N}^{0}$ 4, pp. 365-386. Retrieved z: doi:10.1093/pan/mpiO25.

Key, V.O. (1968). The Responsible Electorate: Rationality in Presidential Voting, 1936-1960, New York: Vintage Books.

Lebo M. \& D. Cassino (2007). "The Aggregated Consequences of Motivated Reasoning and the Dynamics of Partisan Presidential Approval". Political Psychology, Vol. 28, N 6, pp.719-746.

León, Sandra (2010). "Who Is Responsible for What? Clarity of Responsibilities in Multilevel States: The Case of Spain". In: European Journal of Political Research 50: 80-109, 2010 doi: 10.1111/j.1475-6765.2010.01921.x.

Lewis-Beck, Michael S. \& M. C. Ratto (2013). "Economic Voting in Latin America: a General Model." Electoral Studies 32(3):489-493.

Luján D. \& C. López Burian (2016). "El tercer gobierno del Frente Amplio en Uruguay: Supremacía electoral de la izquierda y perspectiva de reformas institucionales". Revista Postdata, 21 (1). 
Luna, J. P. (2002). "¿Pesimismo estructural o voto económico? Sobre la racionalidad agregada del electorado uruguayo". Revista Uruguaya de Ciencia Política, pp. 13: 123-152.

Mc.Allister, I. (1999). "The Economic Performance of Governments". In: Pippa Norris (ed.), Critical Citizens: Global Support for Democratic Government, pp. 188-203. New York: Oxford University Press, 1999.

Mueller, J. E. (1970). "Presidential Popularity from Truman to Johnson". The American Political Science Review, Vol. 64, No 1, pp. 18-34.

Mueller, John. (1973). War, Presidents, and Public Opinion. Lanham, MD: University Press of America.

Newman, B. \& A. Forcehimes (2010). "'Rally Round the Flag' Events for Presidential Approval Research". Electoral Studies, 29(1), 144-154.

O'Donnell, G. (2007). Disonancias: críticas democráticas a la democracia. Buenos Aires: Prometeo Libros.

Pérez-Liñán, A. (2007). Presidential Impeachment and the New Political Instability in Latin America. Cambridge: Cambridge University Press.

Powell G. B. \& G. D. Whitten (1993). "A Cross-National Analysis of Economic Voting: Taking Account of the Political Context." American Journal of Political Science 37(2):391-414.

Przeworski, A., S. Stokes \& B. Manin (1999). Democracy, Accountability and Representation. New York: Cambridge University Press.

Renno, L. \& W. Gramacho (2010). "Let's Blame Everyone: Executive and Legislative Evaluations of Economic Performance in Brazil and Chile." Journal of Politics in Latin America 2(1):53-78.

Rius, A. (1992). "El gobierno, la economía y el hombre de la calle." Revista SUMA 7, Montevideo, pp. 7-35.

Rudolph, T. J. (2003). "Institutional Context and the Assignment of Political Responsibility." Journal of Politics 65(1):190-215.

Samuels, D. (2004). "Presidentialism and Accountability for the Economy in Comparative Perspective." American Political Science Review 98(3):425-436. 
Shapiro R. Y. \& B. M. Conforto (1980). "Presidential Performance, the Economy, and the Public's Evaluation of Economic Conditions". The Journal of Politics, Vol. 42, No 1, pp. 49-67.

Sirin, C. V. \& J. D. Villalobos (2011). "Where Does the Buck Stop? Applying Attribution Theory to Examine Public Appraisals of the President." Presidential Studies Quarterly 41(2):334-357.

Stimson, J. A. (1991). Public Opinion in America: Moods, Cycles, and Swings, Boulder, CO: Westview Press.

Stokes, S. C. (2001). Mandates and Democracy: Neoliberalism by Surprise in Latin America. New York: Cambridge University Press.

Tavits, M. (2007). "Clarity of responsibility and corruption." American Journal of Political Science 51 (1):218-229.

Vairo, D. \& J. R. Rodríguez (2017). "Treinta años de democracia en Uruguay: a modo de balance". 


\section{Anexo}

Gráficos bivariados previos al modelo. Aprobación de la gestión presidencial según variación de economía e intención de voto al partido en el gobierno

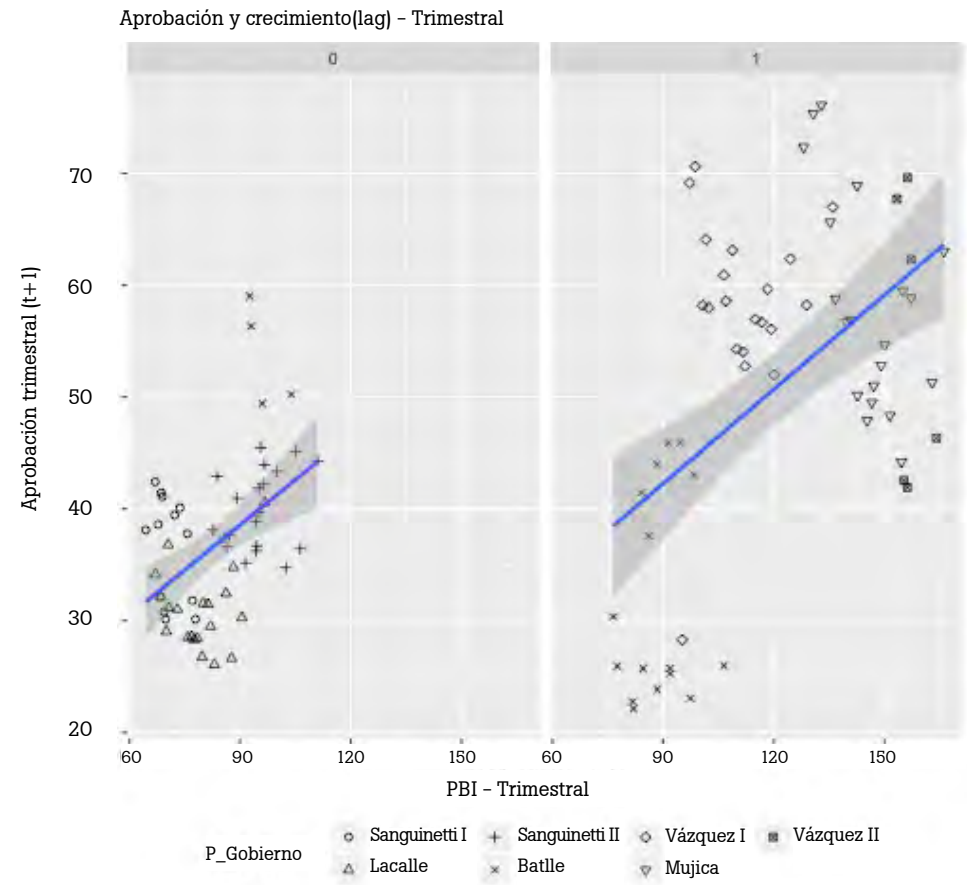




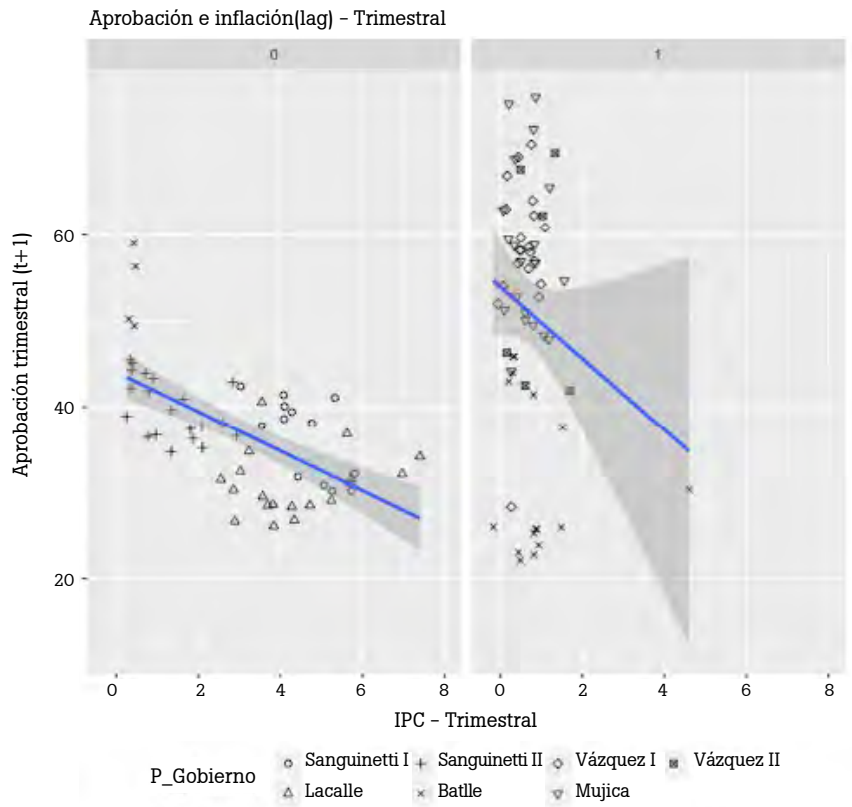

Aprobación y desempleo(lag) - Trimestral

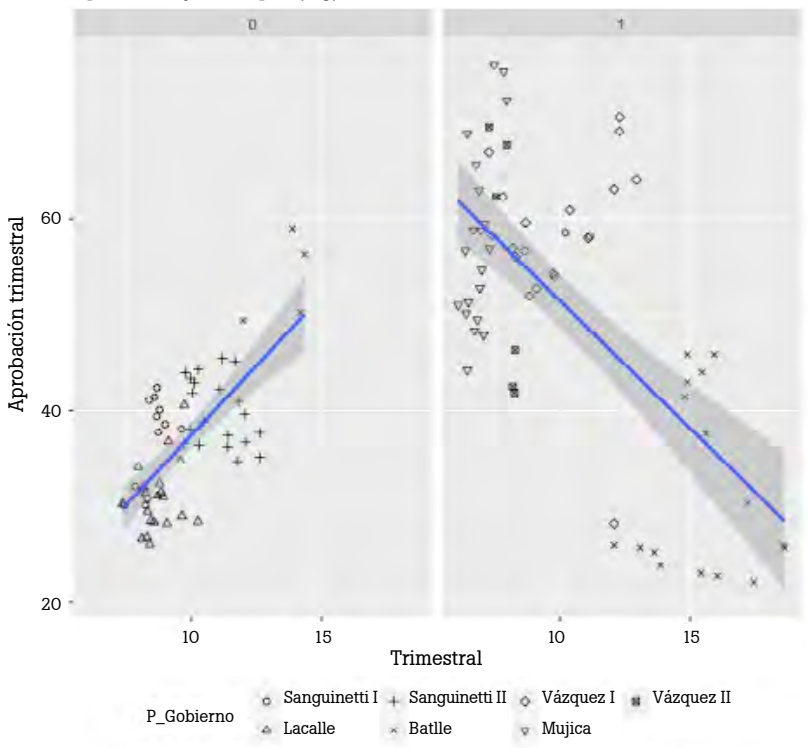




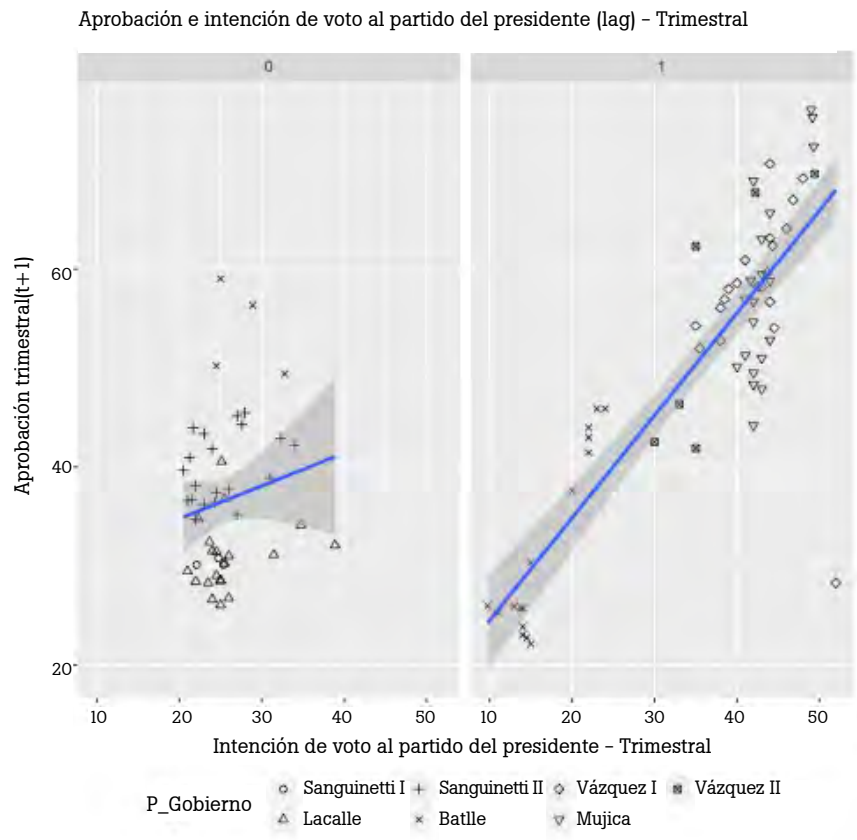

